\title{
Sheep reproductive management
}

Gitation: Reyes-Ramírez, D. S., Osorio-Marín, Y., Hernández-Arzola, M. P., Santiago-Pérez, X., GallegosSánchez, J., \& Fraire-Cordero, S. (2021). Sheep reproductive management. Agro Productividad. https://doi.org/10.32854/agrop. v14i8.2100

Editor in Chief: Dr. Jorge Cadena Iñiguez

Received: March 16, 2021. Accepted: August 29, 2021.

Published on-line: October 12, 2021

This work is licensed under a Creative Commons Attribution-NonCommercial 4.0 International license.

\section{(c) (1) (\$)}

\author{
Reyes-Ramírez, David S. ${ }^{1}$; Osorio-Marín, Yolanda ${ }^{1}$; Hernández-Arzola, Marcia P. ${ }^{1}$; \\ Santiago-Pérez, Xochilt ${ }^{2}$; Gallegos-Sánchez, Jaime ${ }^{1}$; Fraire-Cordero, Silvia ${ }^{3 *}$ \\ 1 Colegio de Postgraduados Campus Montecillo. Carretera Federal México-Texcoco, km 36.5, Texcoco, Edo \\ de México, México. \\ 2 Universidad Autónoma Chapingo, Departamento de Zootecnia, Texcoco, Edo. de México, México. \\ 3 CONACYT-Colegio de Postgraduados Campus Campeche. Carretera Haltunchén-Edzná, km 17.5, \\ Champotón, Campeche, México. \\ * Correspondence: frairec@colpos.mx
}

\begin{abstract}
Objective: To describe some reproductive management programs that allow increasing the productive efficiency of ewes.

Design/methodology/approach: Description of the main hormones and their application in sheep reproductive management protocols. The subjects are reviewed based on academic references as well as on their use in sheep reproductive protocols at the Sheep and Goat Reproduction Laboratory of the Colegio de Postgraduados, Mexico.

Results: Hormones, socio-sexual strategies, reproductive protocols and techniques are tools that improve the reproductive efficiency of ewes during the reproductive season and seasonal anestrus.

Study limitations/implications: The basic techniques of reproductive management and protocols in sheep are mostly available, however, they still have room for improvement, therefore, multiple efforts involving all participants, such as the primary sector, public and private institutions, are required.

Findings/conclusions: Reproductive management is an important pillar for animal production; thus its implementation is fundamental to improve the reproductive and productive efficiency of a herd.
\end{abstract}

Keywords: Reproduction, ewe, reproductive season, seasonal anestrus.

\section{INTRODUCTION}

Sheep production must begin with knowledge of each breed's productive characteristics to select those that have the best productive yield according to the environmental conditions at each region, particularly of each production unit. Subsequently implementing reproductive management programs, fundamental to increase production efficiency.

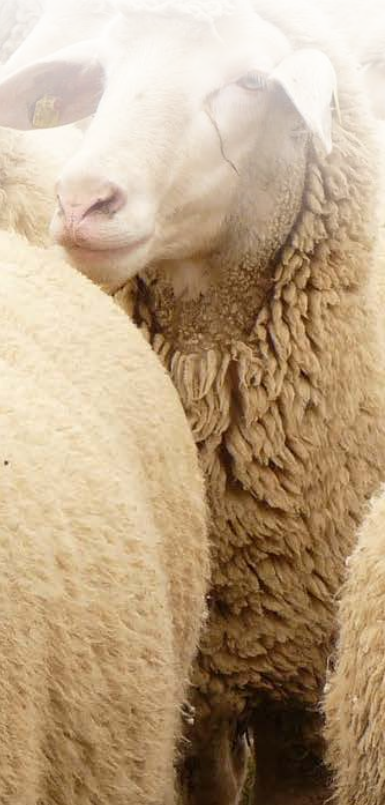


The objective in traditional sheep production systems is to obtain one lambing per year; however, as production systems incorporate technologies, production becomes intensive and management practices incorporate biotechnologies to manipulate reproduction, making it possible to achieve three lambings in two years or five in three.

For example, in an intensive sheep production system, the main objective is to increase their biological efficiency and economic profitability. From the reproductive point of view, they aim to increase the number of born lambs per ewe (prolificacy) and their frequency. This is a complicated task, given that many sheep breeds in the world have a seasonal reproduction rhythm (photoperiod), which is an evolutionary strategy to ensure that the offspring are born at the most adequate time of the year, mainly related to food and temperature. This evolutionary strategy naturally limits ewes' productivity, so it is necessary to implement management strategies to induce reproductive activity during the long days (seasonal anestrus) (Martin et al., 2004) and improve estrus response and ovulation synchronization schemes during the reproductive season.

Thus, reproductive management consists of techniques and strategies that are applied to improve the animal's productivity and should be specific for each breed and environment to optimize the productive performance of the production unit.

\section{Reproductive Season}

At puberty, ewes acquire ovulating capacity (cyclically producing eggs) and manifesting estrous behavior. The reproductive activity of ewes is defined as a series of physiological events that occur during different periods throughout the year; that is, ewes have a reproductive season, alternating with an anestrus period (Figure 1).

The reproductive season is characterized by the presence of regular estrous cycles, estrous behavior and ovulation (Figure 2); in the northern hemisphere, it occurs from August to February (short days) but varies depending on breed and geographic location (latitude). The sheep estrous cycle has an average 17-day duration. The receptivity period is generally 36 to $40 \mathrm{~h}$; however, it varies between breeds, prolific breeds have a longer estrous duration compared to low prolific breeds, for example, the Romanov breed has a $70 \mathrm{~h}$ estrous duration. The females' age is another factor that affects estrus duration; adult females have a longer estrus duration than first-time or pubescent females. The ovulation period is of between 24 and $27 \mathrm{~h}$ after the estrus onset (Robertson, 1977).

\section{Hormones in the estrous cycle}

In the estrous cycle, there is a sequence of cellular events at the ovarian level (follicular development; Figure 2) that are related to endocrine changes. Endocrine control of reproduction is exerted through different hormones secreted by the reproductive axis (hypothalamus, pituitary, ovary and uterus). For example, the ovary secretes progesterone, estradiol and inhibin, among others. The corpus luteum (CL), secretes progesterone to maintain the luteal phase during the estrous cycle or a possible gestation, inhibits new ovulation since progesterone causes an inhibition of the frequency of secretion of $\mathrm{GnRH} /$ LH pulses (gonadotropin-releasing hormone/luteinizing hormone; Figure 3). 


\section{ANNUAL PRODUCTION CYCLE}

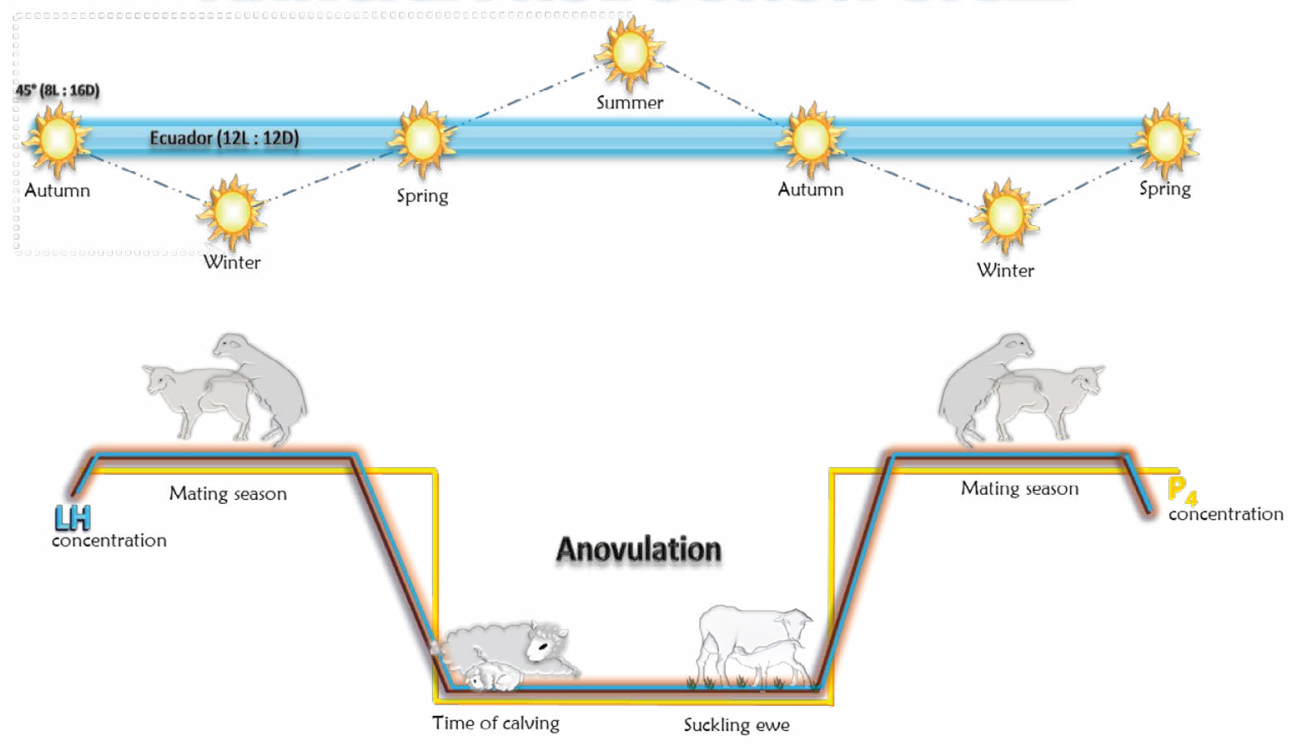

\section{Reproductive}

Anestrus

Reproductive

Figure 1. Schematic representation of the annual production cycle in sheep, showing the different stages of production in their two seasons (reproduction and anestrus) at a $45^{\circ}$ north latitude.

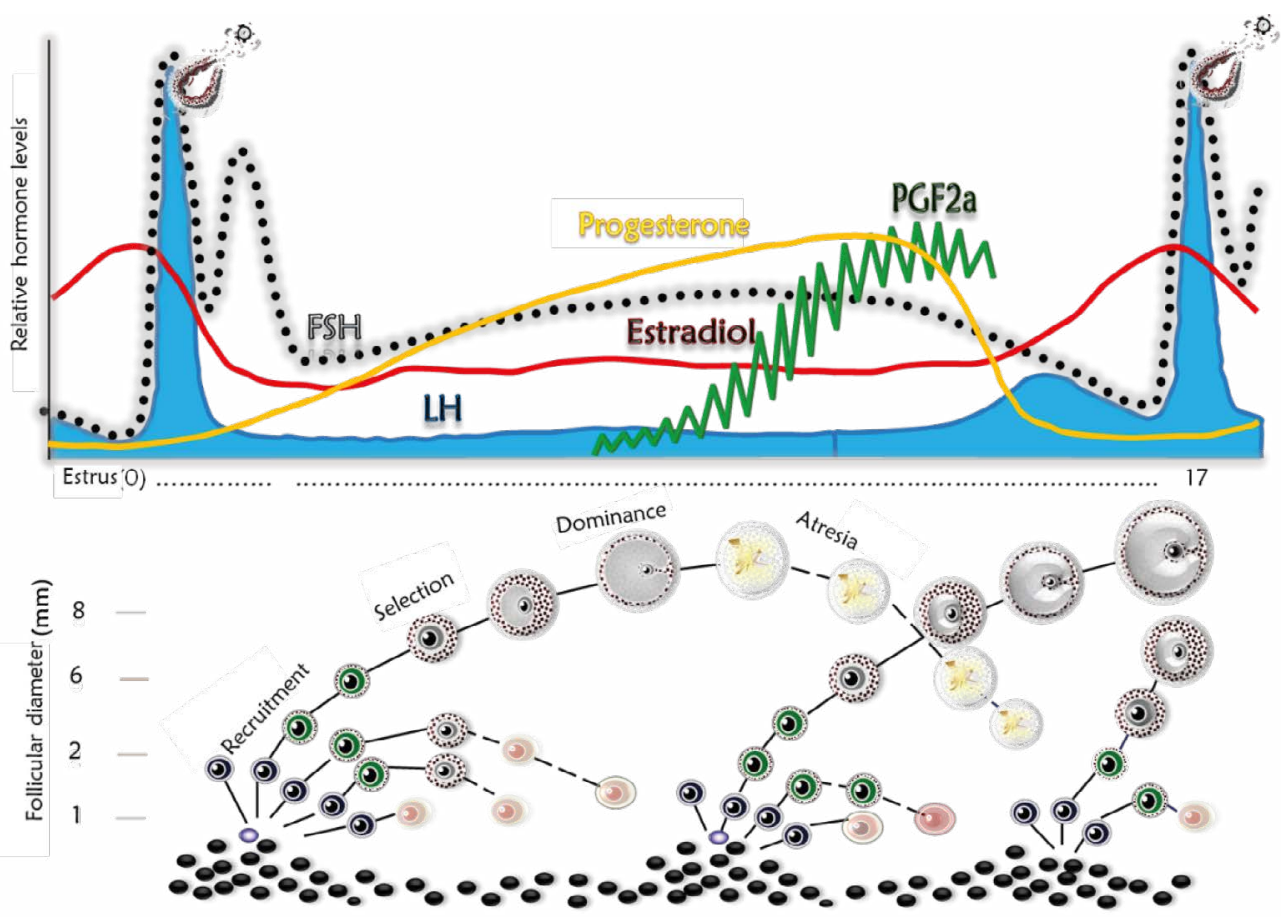

Figure 2. Schematic representation of hormonal profiles and follicular development during the estrous cycle of ewes. FSH (follicle stimulating hormone), LH (luteinizing hormone), PGF2a (prostaglandin F2a), Estradiol $\left(17{ }_{\beta} \mathrm{E}\right)$. 


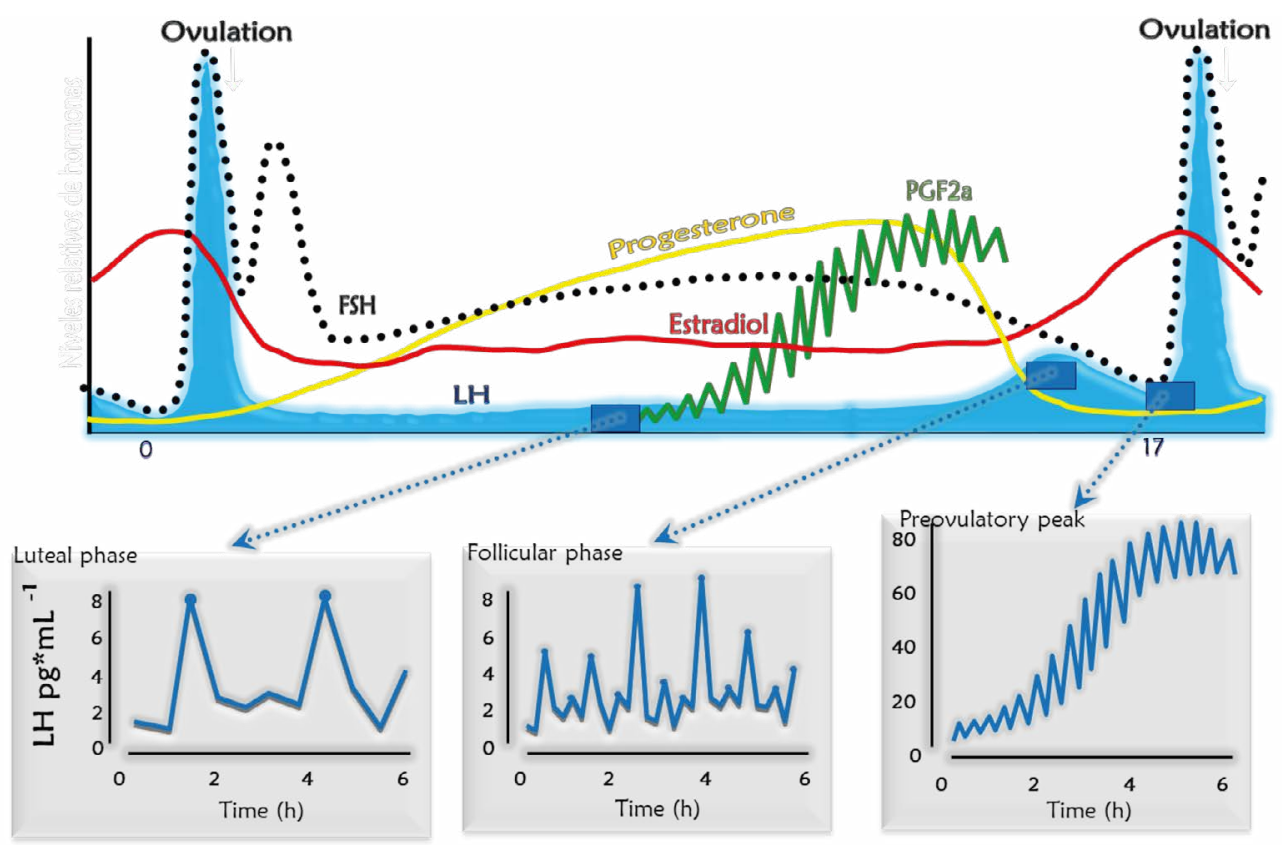

Figure 3. Hormonal profiles during the estrous cycle in ewes and LH secretion frequency.

FSH (follicle stimulating hormone), stimulates the follicular development responsible for producing estrogen and inhibin. Estradiol $\left(17_{\beta} \mathrm{E}\right)$ and inhibin cause negative feedback on FSH secretion (Figure 3; Findlay and Clarke, 1987). Prostaglandin $\mathrm{F}_{2} \alpha\left(\mathrm{PGF}_{2} \alpha\right)$ secretion occurs in the endometrium (Inskeep and Murdoch, 1980) and causes LC lysis by inhibition of lipoprotein uptake that limits intracellular cholesterol transport in the luteal cells, which is induced by oxytocin secreted by the LC, and stimulated by estrogens (Bazer, 1989).

The progesterone secretion decrease, and increased secretion of $17_{\beta} \mathrm{E}$, increases the frequency of GnRH pulse secretion, and therefore, increases the frequency of $\mathrm{LH}$ secretion up to one pulse every hour, causing the preovulatory LH discharge between 2 and $6 \mathrm{~h}$ after the onset of estrus (Figure 3). estrus manifestations occur by an increase in $17_{\beta}$ E levels and a progesterone decrease. Ovulation produces a new CL and the previous endocrine process, which stimulates and controls follicular growth and dynamics at the ovarian level, will repeat (Figure 2) (Goodman and Hodgen, 1983) (Goodman and Hodgen, 1983).

\section{Seasonal anestrus}

In sheep, seasonal anestrus is characterized by the absence of estrous cycles, estrous behavior and ovulation (Figure 1). It occurs during long days when the duration of melatonin secretion is shorter; in the northern hemisphere, it occurs between February and August but varies depending on geographic location (latitude) and breed (Thiéry et al., 2002). During anestrus, estradiol, which is released at basal concentrations, exerts a negative feedback effect at the hypothalamus, specifically in the lateral retrochiasmatic area (nucleus A15), where it acts using dopamine as an intermediate and reduces the GnRH/LH pulses frequency (Gallegos-Sánchez et al., 1997) despite no estradiol receptors were found in A15 nucleus. Therefore, the exact physiological mechanism of this event 
is not clear. However, there is evidence suggesting that GABA (gamma butyric acid) producing neurons present synaptic connections with dopaminergic neurons in nucleus A15 and one of the effects of GABA is to inhibit dopamine synthesis (Bogusz et al., 2008), therefore, GABA secretion reduction in the A15 nucleus causes dopaminergic neurons stimulation and increases dopamine synthesis, which reduces the frequency of GnRH/LH pulse secretion.

Studies in Mexico, to establish the seasonal reproductive behavior of wool sheep, are limited. There are two methodologies to analyze the reproductive seasonality in sheep. The first, relatively simple, consists of the estrus detection, using males with apron, vasectomized, with a deviated penis, or with a testosterone implant or androgenized females. The second is to take blood samples once or twice a week and determine the progesterone concentration, concentrations greater than or equal to $1 \mathrm{ng} \mathrm{mL}^{-1}$ indicate that a female is ovulating; ewes in anestrus have lower than $1 \mathrm{ng} \mathrm{mL} \mathrm{m}^{-1}$ progesterone concentrations (Arroyo et al., 2007).

\section{Reproductive Management: Induction and Synchronization of Estrus and Ovulation}

There are two alternatives to improve production in the reproductive management of a flock; the first relates to the management of the reproductive efficiency of the females (fertility and prolificacy), the second, to the using reproductive biotechnologies through the synchronization and induction of estrus and ovulation, these techniques allow to increase the reproductive efficiency of the sheep.

Manipulation of the timing of estrous onset is essential for good reproductive management; it allows to determine the time of lambing, inducing ovulation during anestrus, estrous synchronizing during the reproductive season, as well as choosing and managing the parental genealogy using techniques such as artificial insemination and embryo transfer.

The ovulation synchronization and induction protocols mentioned below are used in the Sheep and Goat Reproduction Laboratory of the Colegio de Postgraduados, Mexico. Still, there are other drugs and protocols variants in the market that can be used.

\section{Progestogens application}

Protocols for the induction and synchronization of estrus and ovulation are generally based on progestin application. Since the 1950s, various devices have been used to administrate progestogens, which have been evaluated to determine their mode of action and the time at which estrus is initiated. Progesterone or progestogens can be orally, intramuscularly, subcutaneously, or intravaginally administered. Comparative studies in ewes with the most common progestogens: FGA (fluorogestone acetate) and MAP (medroxyprogesterone acetate) have shown similar efficiency.

In ewes, progestogens reach their maximum concentration $48 \mathrm{~h}$ after vaginal introduction of the sponge or device and slowly decrease until the time of withdrawal. Currently, they can be maintained for 9 to 12 days in anestrus and cycling ewes (Figure 4), to overcome the duration of a possible CL in the ovary (Fukui et al., 1999). If it is desired 


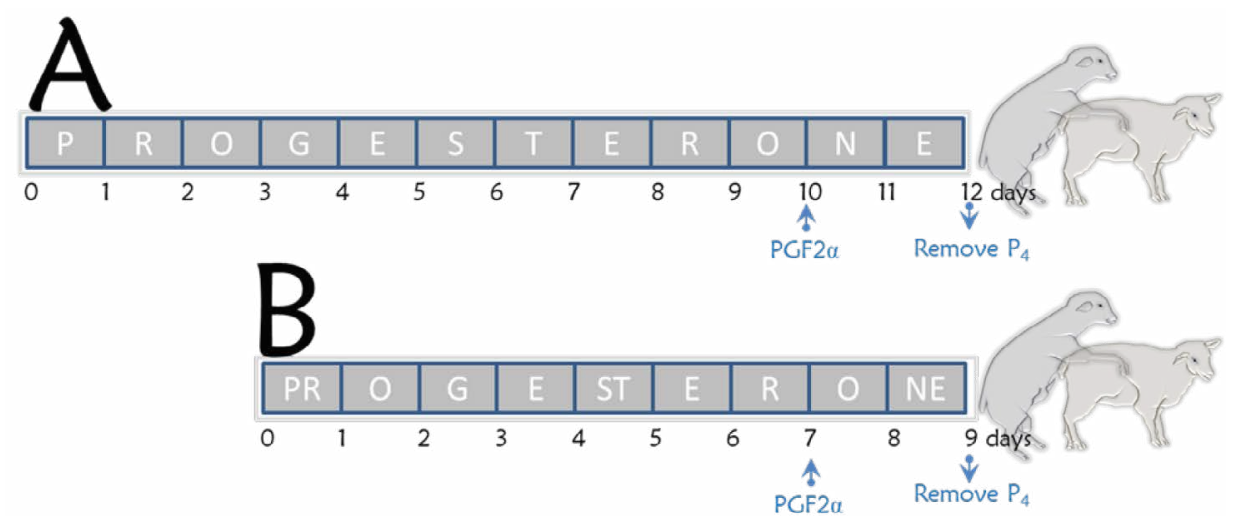

Figure 4. Scheme of synchronization and induction of estrus in seasonal anestrus (A) and reproductive season (B), used in the Sheep and Goat Reproduction Laboratory (LaROCa) at Colegio de Postgraduados.

to inseminate at a fixed time, it is necessary to wait for 48 to $60 \mathrm{~h}$ after withdrawal of the progestogen, a time that should be adjusted according to the administered drugs.

\section{Prostaglandin $\left(\mathbf{P G F}_{2} \alpha\right)$}

Using $\mathrm{PGF}_{2} \alpha$ or its analogs, as a synchronization tool, is limited to cycling ewes, as they cause CL lysis, susceptible to $\mathrm{PGF}_{2} \alpha$ action five days after estrus. Estrus occurs between 36 and $144 \mathrm{~h}$ after $\mathrm{PGF}_{2} \alpha$ administration, almost $100 \%$ of cycling ewes respond to 2 prostaglandins injections at a 9 to 12 days interval (Figure 5). For this effect, a 125 $\mathrm{mg}$ cloprostenol dose is effective and, in the case of natural $\mathrm{PGF}_{2} \alpha$, a dose of $15 \mathrm{mg}$ is recommended.

\section{Equine Chorionic Gonadotropin (eCG)}

$\mathrm{eCG}$ is a glycoprotein produced in the endometrial ridges of pregnant mares; its activity is similar to that of FSH, but it also has LH action. Its usage is mainly due to its low cost, availability in the market and its long half-life (approximately three days in the ewe), this is due to the amount of sialic acid (Schams et al., 1978).

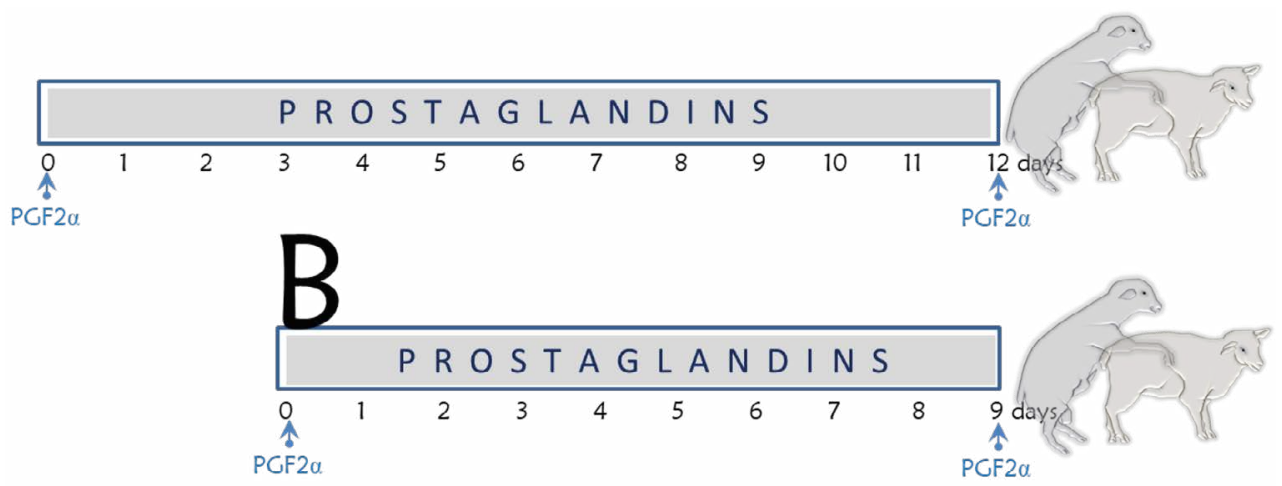

Figure 5. Oestrus synchronization scheme applying $\mathrm{PGF}_{2} \alpha$, used in the Sheep and Goat Reproduction Laboratory (LaROCa) of the Colegio de Postgraduados. 
eCG is used in several protocols for induction and estrus synchronization and ovulation; it is administered by intramuscular injection two days before or at the time of the removal of the progestogen-impregnated device. It stimulates the recruitment of small follicles, follicular development and increases the ovulatory rate, which allows estrus and ovulation to occur rapidly and homogeneously. The doses of eCG vary from 200 to $600 \mathrm{IU}$, depending on the breed, time of year, age and physiological state of the females, thus promoting the development of a greater number of follicles, increasing the ovulation rate by up to $30 \%$. The dose of eCG is one of the most important variables in using this type of treatment; for example, the dose in wool-producing ewes is approximately (depending on the weight of the female) $500 \mathrm{IU}$ and in hair ewes, it is 300 to $350 \mathrm{IU}$ (Figure 6). An inadequate dose may cause a failure in the stimulation, doses higher than that recommended cause an undesired increase in the ovulation rate, and, therefore, multiple lambings and the birth of lambs with low survival capacity.

\section{Male effect}

Currently, and almost in all sheep production systems, the international trend is to reduce to the maximum the drug application to increase the reproductive efficiency of sheep. Therefore, new reproductive management strategies have been implemented, such as socio-sexual effects, mainly the "male effect", which has been shown to work by increasing the frequency of $\mathrm{GnRH} / \mathrm{LH}$ pulse secretion (Figure 7).

Although there is controversy in the ram's ability to induce ovulation, mainly in highly seasonal breeds, such as the Suffolk, since the sudden introduction of the ram in the middle of the seasonal anestrus does not always produce the expected effect (ovulation); however, it has been shown that the lack of ram stimulation to induce ovulation under these conditions in the Suffolk breed is not due to the absence of response in the increase of pulsatile LH secretion. One of the advantages of using the male effect is that it induces an increase in pulsatile LH secretion and ovulation when females are more sensitive (Hawken et al., 2005). For example, in Mexico, in ewes in anestrus (seasonal or postpartum), the sudden introduction of the male causes the resumption of ovarian activity; from the total number

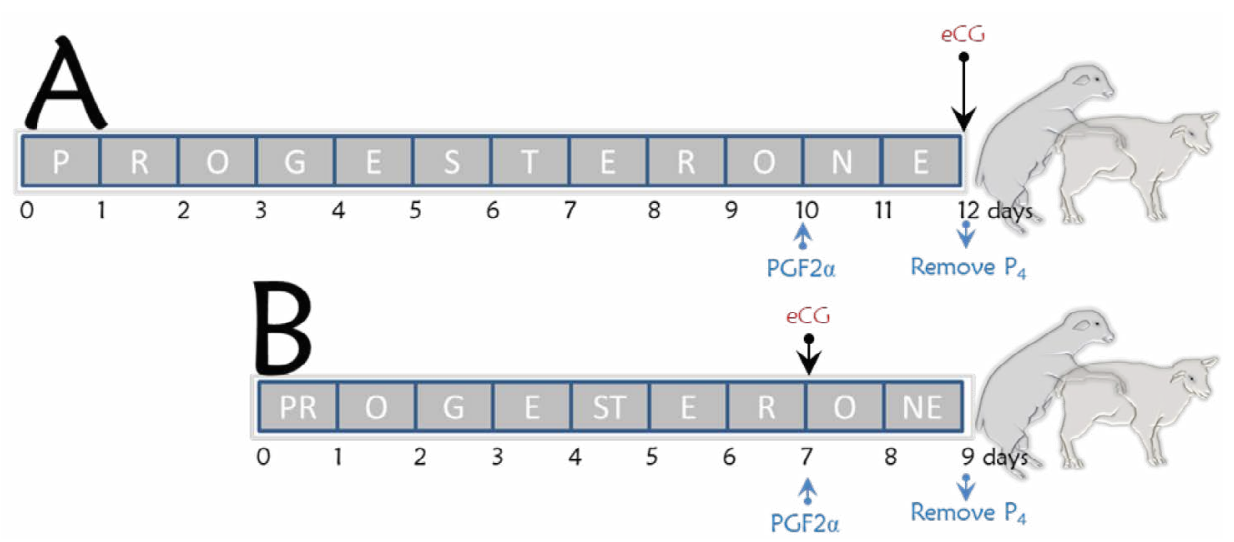

Figure 6. Synchronization scheme and induction of estrus using eCG, in seasonal anestrus (A) and reproductive season (B), at the Laboratory of Reproduction of Sheep and Goats (LaROCa) of the Colegio de Postgraduados. 


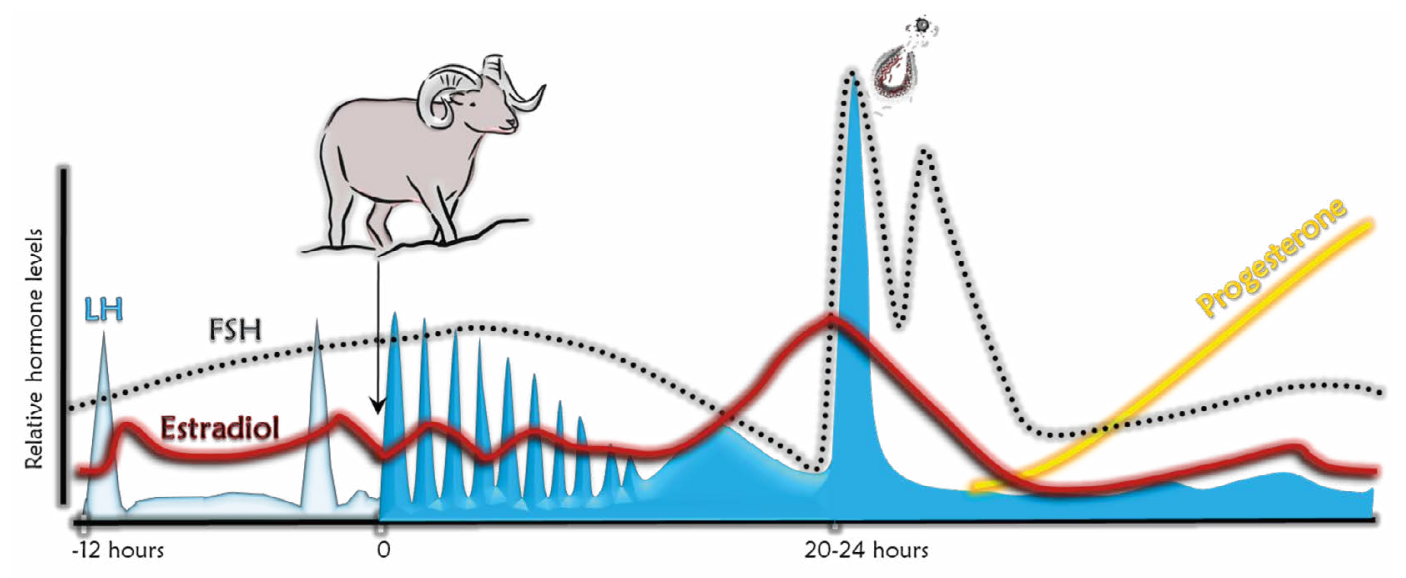

Figure 7. Physiological events triggered by the "male effect". Increase of the frequency of secretion of GnRH/ LH pulses.

of ewes exposed to the sire, a high percentage ovulate within the first three to five days. It is suggested that to obtain a higher male effect response (stimulation of anestrus females), males should be isolated (not in contact with females) because the male should represent a "novel" stimulus.

\section{Pregnancy diagnosis}

The productive yields of flocks can be improved with an early pregnancy diagnosis, since it reduces the interval between lambings and facilitates the homogeneous management of animals, for example, ewes can be managed by groups, a new estrus can be induced in females that did not become pregnant and a feed supplement can be offered to the pregnant ones.

Pregnancy diagnosis is mainly done with ultrasound and a transabdominal probe; it is also possible to assess the number of embryos and the viability of the pregnancy. The diagnosis of gestation can be made from 24 days after insemination on (natural or artificial), although it is better to diagnose gestation between day 30 and 35, since the embryo presence and especially its cardiac activity increases the efficiency of the diagnosis up to $90 \%$, reducing errors due to confusion of embryonic vesicles with intestinal loops, cross-sections of blood vessels, a localized accumulation of liquid inside the uterine horns or with possible uterine pathologies.

The assessment of the number of embryos and the separation of single, double, or multiple gestations is very useful in sheep farming. This assessment should be done by a complete sweep of the maternal genital tract, differentiating each embryo or fetus individually in the different sections of each uterine horn. The assessment of the number of embryos should be done between 50 and 55 days, where about $85 \%$ is obtained for single births and 100\% for multiple births. The main errors occur by underestimation if one of the fetuses is not detected or by overestimation if the same fetus is considered as two different ones when two embryos are not simultaneously displayed on the screen (Dawson et al., 1994). 


\section{CONGLUSIONS}

The techniques for artificial insemination and synchronization and induction of estrus, socio-sexual effects (male effect) and gestation diagnosis are tools that improve the reproductive efficiency of sheep, so their application is essential. It is important to mention that there are other techniques that in addition to the above mentioned, can improve sheep production, such as: in vitro embryo production, transgenesis and cloning.

\section{REFERENGES}

Arroyo, L.J., Gallegos-Sánchez, J., Villa-Godoy, A., Berruecos, J.M., Perera, G., Valencia, J. (2007). Reproductive activity of Pelibuey and Suffolk ewes at $19^{\circ}$ north latitude. Animal Reproduction Science, 102, 24-30. Doi: 10.1016/j.anireprosci.2006.09.025.

Bazer, F.W. (1989). Establishment of pregnancy in sheep and pigs. Reproduction, Fertility and Development, 1(3), 237-242.

Bogusz, A.L., Hardy, L.S., Lehman, M.N., Connors, J.M., Hileman, S.M., Sliwowska, H., Billings, H.J., McManus, G.J., Valent, M., Singh, S.R., Nestor, G.C., Coolen, L.M., Goodman, R.L. (2008). Evidence that $\alpha$-aminobutyric acid is part of the neural circuit mediating estradiol negative feedback in anestrous ewes. Endocrinology, 149, (6). 2762-2772. Doi: 10.1210/en.2007-1362

Dawson, L.J., Sahlu, T., Hart, S.P., Detweiler, G., Gipson, T.A., Teh, T.H., Henry, G.A., Bahr, R.J. (1994). Determination of fetal number in Alpine does by real-time ultrasonography. Small Ruminant Research, 14(3), 225-231.Doi: 10.1016/0921-4488(94)90045-0

Findlay, J.K., Clarke, I.J. (1987). Regulation of the secretion of FSH in domestic ruminants. Journal of Reproduction and Fertility Supplement, 34, 27-37.

Fukui, Y., Ishikawa, D., Ishida, N, Okada, N., Itagaki, R., Ogiso, T. (1999). Comparison of fertility of estrous synchronized ewes with four different intravaginal devices during the breeding season. Journal of Reproduction and Development, 45(5), 337-343. Doi: 10.1262/jrd.45.337

Gallegos-Sánchez, J., Delaleu, B., Caraty, A., Malpaux, B., Thiéry, J.C. (1997). Estradiol acts locally within the retrochiasmatic area to inhibit pulsatile luteinizing-hormone release in the female sheep during anestrus. Biology of Reproduction, 56, (6). 1544-1549. Doi: 10.1095/biolreprod56.6.1544

Goodman, A.L., Hodgen, G.D. (1983). The ovarian trial of the Primate Menstrual Cycle. Recent Progress in Hormone Research, 39, 1-73.

Hawken, P.A.R., Beard, A.P., O’Meara, G.M., Duffy, P., Quinn, K.M., Crosby, T.F., Boland, M.P., Evans, A.C.O. (2005). The effects of ram exposure during progestagen oestrus synchronisation and time of ram introduction post progestagen withdrawal on fertility in ewes. Theriogenology, 63(3), 860-871. doi: 10.1016/j.theriogenology.2004.05.007

Inskeep E.K., Murdoch, W.J. (1980). Relations of ovarian functions to uterine and ovarian secretion of prostaglandins during the estrous cycle and early pregnancy in the ewe and cow. International Review of Physiology, 22, 325-356.

Martin, G.B., Milton, J.T.B., Davidson, R.H., Banchero, G.E., Lindsay, D.R., Blache, D. (2004). Natural methods for increasing reproductive efficiency in small ruminants. Animal Reproduction Science, 82-83, 231-245. Doi: 10.1016/j.anireprosci.2004.05.014

Robertson, H.A. (1977): Reproductive in the ewe and the goat. En H. H. Cole and P.T. Cupps (Eds.), Reproduction in domestic animals (pp. 475-498). Academic Press.

Schams, D., Menzer, G.H., Schallemberger, E., Hoffmann, B., Hahn, J., \& Hahn, R. (1978). Some studies on pregnant serum gonadotrophin (PMSG) and on endocrine responses after application for superovulation in cattle. En J. M. Sreenan (Ed.), Control for reproduction in the cow (pp. 122-143). Martinus Nijhoff Publishers.

Thiéry, J.C., Chemineau, P., Hernández, X., Migaud, M., Malpaux, B. (2002). Neuroendocrine interactions and seasonality. Domestic Animal Endocrinology, 23(1-2), 87-100. Doi: 10.1016/S0739-7240(02)00148-0 